www.jmscr.igmpublication.org

Index Copernicus Value: 79.54

ISSN (e)-2347-176x ISSN (p) 2455-0450

crossref DOI: https://dx.doi.org/10.18535/jmscr/v7i6.101

\title{
Primary Tubercular Cervicitis: A Common Disease at an Uncommon Site
}

\author{
Authors \\ Dr Ashok Kumar Dash ${ }^{1}$, Dr Shushruta Mohanty ${ }^{2 *}$, Dr Sanghamitra Sahoo ${ }^{3}$, \\ Dr Milan Tripathy \\ ${ }^{1}$ Associate Professor, Dept of Pathology, M.K.C.G. Medical College, Berhampur \\ ${ }^{2,3}$ Senior Resident, Dept of Pathology, M.K.C.G. Medical College, Berhampur \\ ${ }^{4}$ Post Graduate, Department of Pathology, M.K.C.G. Medical College, Berhampur \\ *Corresponding Author \\ Dr Shushruta Mohanty \\ Senior Resident, Dept of Pathology, M.K.C.G. Medical College, Berhampur, India
}

\begin{abstract}
Tuberculosis of cervix is a rare form of genital Tuberculosis. As it has no specific symptoms and signs, so a high index of suspicion of TB in females with abnormal vaginal discharge is required while screening cervical smears, especially from TB endemic areas. Non pulmonary Tuberculosis are common in this parts of the state (i.e in South Odisha, Berhampur) in different parts of the body ranging from scrotum to TB osteomyelitis. We present a case of a 40 year female presenting with a foul smelling discharge per vagina who was suspected of carcinoma cervix clinically and later diagnosed through pap smear and on histopathology to be a case of cervical TB.
\end{abstract}

\section{Introduction}

Tuberculosis is highly prevalent and considered as major socioeconomic burden in India. Genitourinary tuberculosis accounts up to $5-24$ $\%$ of cases that is usually seen in young women of child bearing age. Tuberculosis more frequently affects the upper genital tract-namely, the fallopian tubes and endometrium and the ovary ${ }^{[1]}$. Tuberculosis of the cervix is rare incidental finding and accounts to $0.1-0.65 \%$ of all cases of tuberculosis ${ }^{[2]}$. We present such a case due to rarity of this condition and sometimes it can clinically mimick carcinoma cervix mostly in post menopausal females. ${ }^{[1]}$

\section{Case Report}

A 40 years old lady (Para 1 living 1), manual labourer by occupation, presented with chief complaint of foul smelling discharge per vagina for one year. There was no history of bleeding per vagina, itching or any local lesion. Past history of the patient was insignificant .There was history of recent weight loss, but no history of fever, night sweats, or any exposure to tuberculosis in the past. General physical examination was essentially normal. Per abdomen examination was normal with no organomegaly. Per speculum examination revealed an unhealthy looking cervix which was grossly erythematous, congested and bled on touch. There was no hypertrophy, growth or ulceration. On bimanual examination, uterus 


\section{JMSCR Vol||07||Issue||06||Page 594-598||June}

was anteverted and normal in size. Vaginal walls were healthy and there was no adnexal mass or forniceal tenderness. Per rectal examination was normal.

Laboratory investigations revealed a raised ESR of $65 \mathrm{~mm}$ fall in first hour and positive Mantoux test $(23 \mathrm{~mm})$. All other hematological and biochemical parameters were normal. Chest radiograph was normal. Antibody tests for human immunodeficiency virus (HIV) and syphilis infection were negative and the patient did not have any kind of immunodeficiency. Routine cervical Papanicolaou (Pap) smear showed focal areas of macrophages, clusters of epithelioid cells and a few Langhan's type of giant cells along with dense inflammation. A cytological diagnosis of granulomatous cervicitis was made.

Colposcopic examination showed increased vascularity with mild acetowhite and iodine negative areas. The lesion was excised under colposcopic guidance and sent for histopathological examination. Grossly we received 2 containers one labeled as cervical biopsy and second as endometrial curretings containing multiple bits of grayish brown tissue bits altogether measuring 2x1 cms. Microscopic examination of cervical biopsy showed endocervical lining with the underlying subepithelial tissue showing numerous epithelioid cell clusters, Langhans giant cells along with focal areas of necrosis along with dense acute and chronic inflammatory cells. Endometrial curettings showed endometrial glands in proliferative phase with no evidence of TB. Based on histopathological findings a diagnosis of cervical tuberculosis was rendered.

To search for possible mode of transmission the patient was then evaluated for primary pulmonary TB which turned out to be negative. Spouse of the patient was evaluated for pulmonary and genitourinary $\mathrm{TB}$ by doing urine and semen analysis for AFB as well as USG of the testes and the epididymis, but the possible mode of transmission couldn't be detected. The patient was started on anti-tuberculous therapy (ATT) and a speculum examination done after the completion of the therapy, revealed a normal looking cervix.

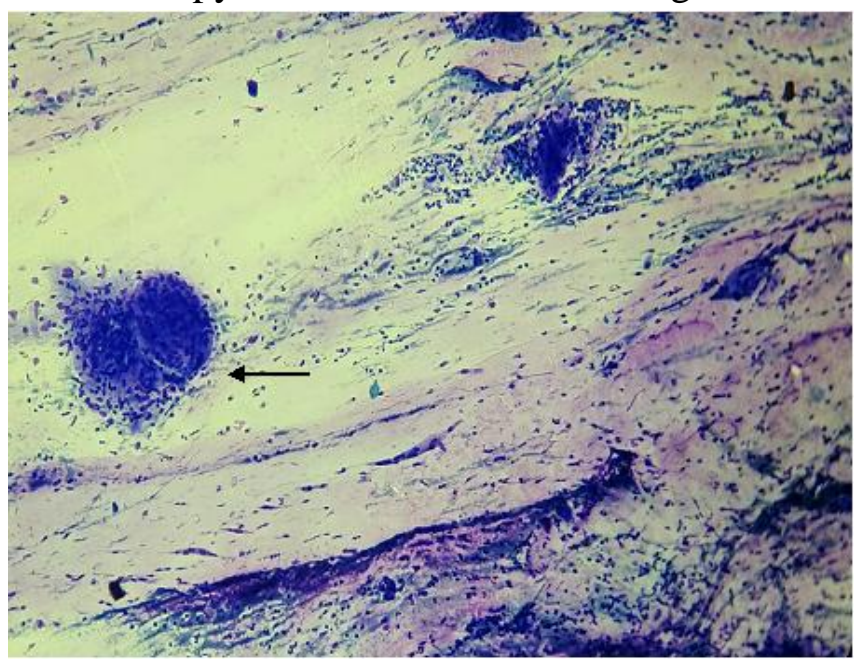

Fig 1 (a) Scanner view [40X] Showing Cluster of epithelioid cells (black arrow) on Pap smear

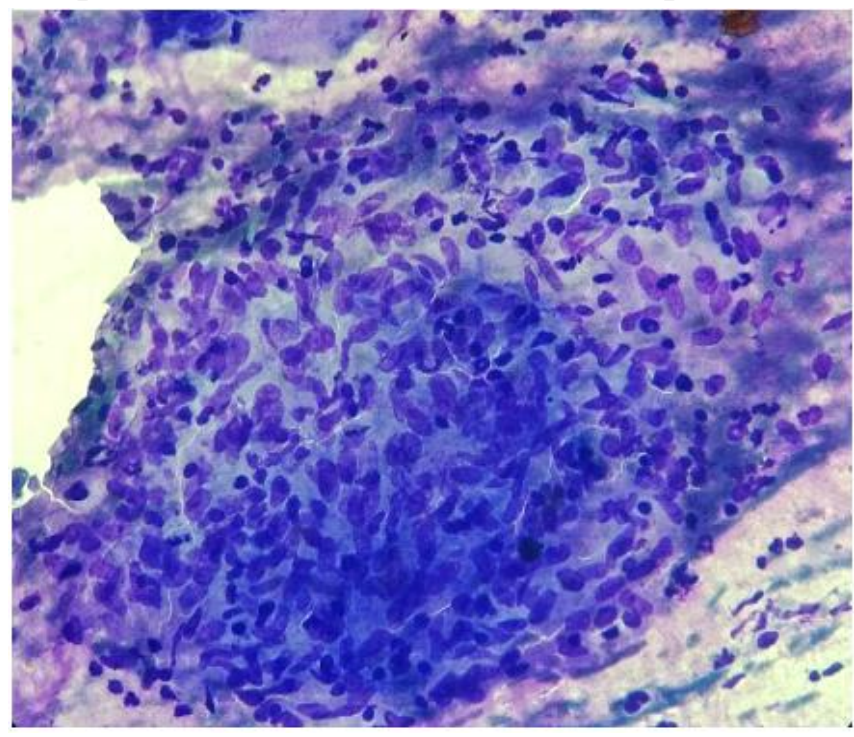

Fig 1 (b) LP 100X- Showing epithelioid cell cluster

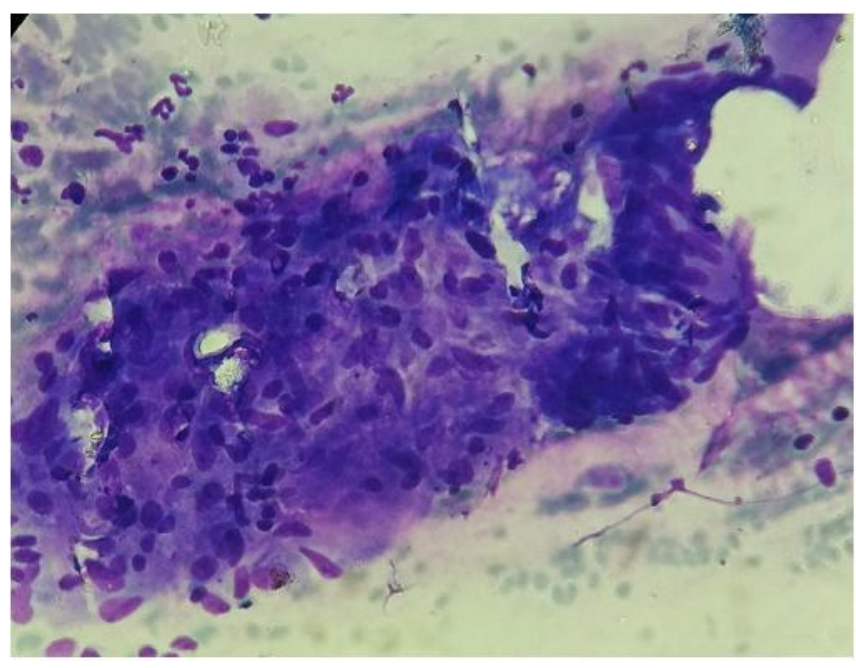

Fig 1 (C) Low power view [100X]- Another area of epithelioid cell clusters 


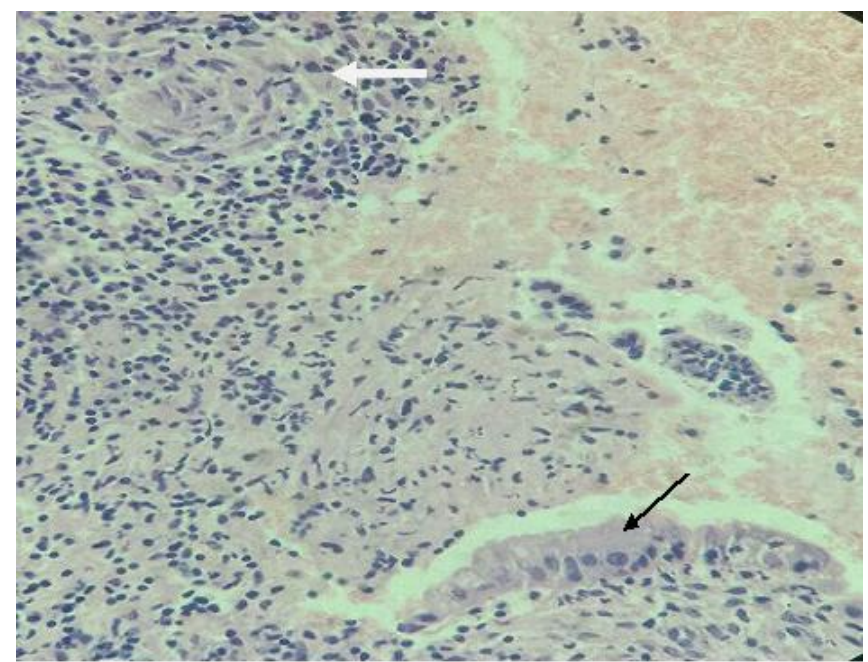

Fig 2(a) Histopathology Low Power 100 XShowing a focus of granuloma(white arrow) and endocervical glands( black arrow)

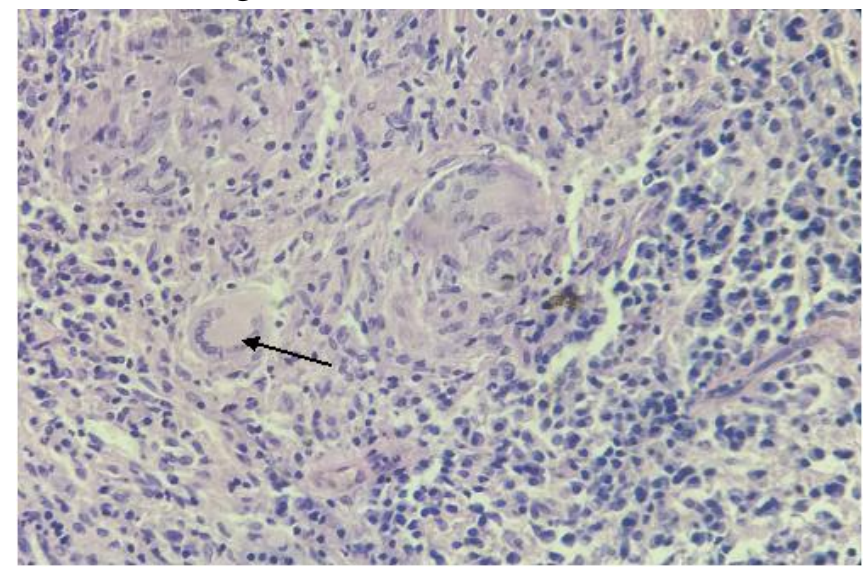

Fig 2(b)

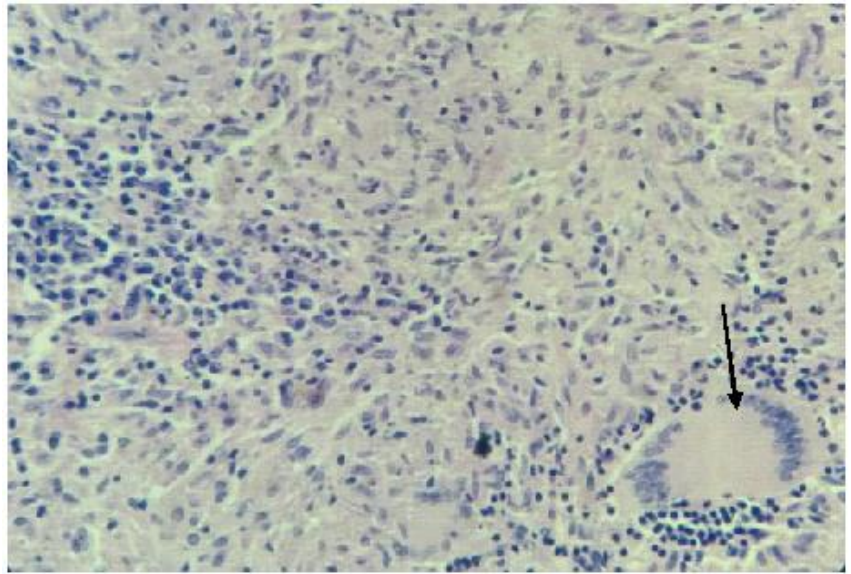

Fig 2 (b) (c)- Low power view [100x] Showing Langhan's Giant cells (black arrows) and mixed inflammatory infiltrate.

\section{Discussion}

Cervical tuberculosis is rare. It is uncommon in developed countries however its occurrence still persists in developing countries like Africa and
India $^{[3]}$. It is often difficult to acess the true magnitude of TB of female genital tract as it is usually asymptomatic and more over rural ladies don't visit physicians out of ignorance for which diagnosis is often delayed. Its incidence has been recently increased especially in areas where HIV and $\mathrm{TB}$ are endemic ${ }^{[4]}$. It is also seen to be associated with cases of infertility among Indian women in about $5-16 \%$ of cases ${ }^{[5]}$.

Females who are in $2^{\text {nd }}$ to $3^{\text {rd }}$ decade (reproductive age group) are more prone to infection (TB) indicating its hormone dependance of infection. Genital tract TB usually presents with infertility, abnormal vaginal bleeding, Amenorrhoea, abdominal pain, pelvic pain, and constitutional symptoms ${ }^{[6]}$. But upto $50 \%$ cases are usually asymptomatic. On examination $90 \%$ of cases the cervix may appear normal to inflamed or may present with nonspecific macroscopic changes like proliferative growth to ulcerative/ hypertrophic nodular lesions ${ }^{[7]}$. Sometimes in premenopausal age group the lesion may mimic carcinoma of cervix both grossly and in colposcopy ${ }^{[8]}$. Four types of tuberculous invasion of cervix have been distinguished: ulcerative, military, papillary and interstitial. The ulcerative type is usually characterized by a single lesion, the edges of which are rather well defined. The ulcer bleeds easily upon contact but less so than in instances of carcinoma. The papillary type may be confused with carcinoma, which it may resemble closely. In the miliary variety, the cervix is enlarged and small military tubercles may be visible on the surface. The interstitial type appears first in the substance of the cervix, forming a nodule which may become necrotic. The necrotic material may be discharged, leaving a cavity ${ }^{[9]}$

Tuberculosis of cervix is very rare as cervix is resistant to $\mathrm{TB}$ infection. The underlying mechanism to this protective effect is attributed mainly to the immunity offered by stratified squamous epithelium of the ectocervix to the penetration of tubercle bacilli and great vascularity of its mucosa and moreover the cervical mucus, is also known to have some 
antibactericidal action ${ }^{[10]}$ Its resistance is however undermined by repeated trauma in active sex life and trauma during labour. Lymphatic spread or direct infection is the mode of involvement of cervix. Pelvic organs are infected from a primary focus, usually the chest, by haematogenous spread $^{[11]}$. Rarely cervical TB can be a primary infection introduced by a sexual partner with tuberculous epididymitis or other genitourinary disease $^{[12]}$

Gold standard criteria for diagnosis is isolation of tubercular bacilli on microscopy and culture. Many cases of Non pulmnary Tuberculosis are paucibacillary lesions, which on cytology and Histopathology study do not show AFB positivity. Hence, one relies on culture for its diagnosis but still then a third of cases are culture negative. Molecular probes although sensitive than culture but have reduced specificity. Therefore, the presence of typical granulomas is considered sufficient for its diagnosis if other causes of granulomatous cervicitis are excluded or a primary focus has been identified. The differential diagnosis for granulomatous diseases include sarcoidosis, crohn's disease, actinomycosis, leprosy, granuloma inguinale, lymphogranuloma venereum, syphilis, histoplasmosis, brucellosis, berylliosis, silicosis, tularemia, schistosomiasis, filariasis and foreign body reaction ${ }^{[13]}$. Cervical cytology being a non invasive tool is quite useful in identifying cervical TB as seen in our case and supported by many authors. Final diagnosis of cervical TB is usually made by histopathological examination of cervical punch biopsy specimem. Microscopically there will be an extensive chronic inflammation with the presence of caseating or noncaseating granulomas in most of the cases.

\section{Conclusion}

Normally cervical TB patients shows good response to 6 months of antitubercular therapy. So awareness and proper follow up of cervical TB patients is necessary as a mark to acess the treatment that can be confirmed by serial biopsies. Howerver owing to the widespread nature of cervical TB to endometrium and fallopian tubes and subsequent healing by fibrosis, fertility in future even after treatment is still questionable. Cervical TB should be included in differential diagnosis while dealing with abnormal cervical lesions in areas where HIV and TB are endemic.

\section{References}

1. Chowdhury NNR. Overview of tuberculosis of the female genital tract. J Indian Med Assoc 1996;94:345-61.

2. Lamba H, Byrne M, Goldin R, Jenkins C. Tuberculosis of the cervix: Case presentation and a review of the literature. Sex Transm Inf 2002;78:63-6.

3. Samantaray S, Parida G, Rout N, Giri SK, Kar R. Cytologic detection of tuberculous cervicitis. Acta Cytol.2009;5:594-6. [PubMed].

4. Akhlaghi F, Hamedi AB. Postmenopausal tuberculosis of the cervix, vagina and vulva. The Internet Journal of Gynecology and Obstetrics 2004; 3:1-4.

5. Roy A, Mukherjee S, Bhattacharya S, Adhya S, Chakraborty P: Tuberculous endometritis in hills of Darjeeling:a clinicopathological and bacteriological study Indian J Pathol Microbiol 1993;36:361-9.

6. Wadhwa N, Singh UR, Saith S. A report of two unsuspected cases of cervical tuberculosis. Indian J Pathol Microbiol. 2005;3:390-2. [PubMed].

7. Misch KA, Alison S, Deirdre T, O'Sullivan JC, Onuigbo W. Tuberculosis of the cervix: Cytology as an aid to diagnosis. J Clin Pathol. 1976;29:3136. [PMC free article] [PubMed].

8. Bhambani S, Das DK, Singh V, Luthra UK. Cervical tuberculosis with carcinoma in situ: A cytodiagnosis (letter). Acta Cytol 1985;29:87-8. 
9. Carter J, Peat B, Dalrymple C, Atkinson K. Cervical tuberculosis- case report. Aust NZ J Obstet Gynaecol 1989;29:270-1.

10. Elkattan E, AbdElBadei M, Hettow H, Hussein E, Assaad J. Tuberculous cervicitis mimicking cancer cervix: A case study. Middle East Fertil Soc J 2014;19:75-7.

11. Richards MJ, Angus D. Possible sexual transmission of genitourinary tuberculosis. Int J TB Lung Dis 1998;2:439.

12. Carter JR. Unusual presentations of genital tract tuberculosis. Int J Gynaecol Obstet 1990;33:171176

13. Koller AB: Granulomatous lesions of the cervix uteri in black patients. South Afr Med J 1975, 49:1228-32. 